\title{
CRESCIMENTO INICIAL E TEOR NUTRICIONAL DO MARACUJAZEIRO AMARELO SUBMETIDO À ADUBAÇÃO COM DIFERENTES FONTES NITROGENADAS ${ }^{1}$
}

\author{
PAULO CESAR DOS SANTOS ${ }^{2}$, LUCIANO CARNIELLO LOPES ${ }^{3}$, SILVIO DE JESUS FREITAS ${ }^{4}$, \\ LILIANE BARROSO DE SOUSA ${ }^{5}$, ALMY JUNIOR CORDEIRO DE CARVALHO ${ }^{6}$
}

RESUMO - O trabalho teve como objetivo avaliar a influência de diferentes fontes nitrogenadas sobre o crescimento inicial e o teor de nutrientes em folhas do maracujazeiro-amarelo. Para isto, foi instalado um experimento em DBC (delineamento em blocos casualizados), com quatro repetições em fatorial 4X5, sendo quatro fontes de nitrogênio (esterco bovino, esterco bovino + sulfato de amônio, esterco bovino + nitrato de amônio e esterco bovino + ureia) e cinco épocas de coleta de plantas $(66 ; 82 ; 98 ; 111$ e 127 dias após a semeadura). As plantas foram conduzidas em vasos de $30 \mathrm{dm}^{3} \mathrm{e}$ em condições de casa de vegetação. Com os resultados obtidos, foi possível concluir que o tratamento contendo apenas esterco bovino apresentou menor número de folhas por planta, menor área foliar, menor massa seca da parte aérea, menores valores de índice SPAD e os menores teores de $\mathrm{N}$ e $\mathrm{Mg}$, quando comparado com os demais tratamentos. Para massa seca de raiz, as plantas submetidas ao tratamento com apenas esterco bovino apresentaram resultados superiores. Termos para indexação: Passiflora edulis, esterco bovino, nitrogênio, nutrientes foliares.

\section{INITIAL GROWTH AND NUTRITIONAL CONTENT OF YELLOW PASSION FRUIT SUBJECTED TO FERTILIZATION WITH DIFFERENT NITROGEN SOURCES}

\begin{abstract}
This study aimed to evaluate the influence of different nitrogen sources, on the early development and on the leaves nutrient content of yellow passion fruit. An experiment was conducted in randomized block design with four replications in a 4X5 factorial, four sources of nitrogen (manure, cattle manure + ammonium sulfate, cattle manure + ammonium nitrate + urea and cattle manure ) and five stages of plants collection $\left(66,82,98,111\right.$ and 127 days after sowing). Plants were conducted in $30 \mathrm{dm}^{3}$ pots under greenhouse conditions. The treatment containing only manure showed a lower number of leaves per plant, reduced leaf area, reduced shoot dry mass, lower SPAD index and lower levels of $\mathrm{N}$ and $\mathrm{Mg}$, when compared with other treatments. Concerning root dry mass, plants subjected to treatment with only manure showed superior results. Index terms: Passiflora edulis, manure, nitrogen, foliar nutrient.
\end{abstract}

\section{INTRODUÇ̃̃O}

Embora seja considerada recente a exploração comercial, a cultura vem-se tornando uma frutífera de expressiva importância econômica pelo aproveitamento total do fruto, em que a polpa se presta para o consumo in natura e industrial, as cascas servem de ração ou como adubo orgânico e das sementes pode-se proceder à extração de óleo (COSTA et al., 2008).

Apesar da grande variabilidade de espécies existentes em nosso País, os cultivos comerciais baseiam-se quase que exclusivamente em Passiflora edulis f. flavicarpa (maracujá-amarelo ou maracujá-azedo), ocupando cerca de $95 \%$ dos pomares comerciais. Os demais 5\% encontram-se divididos entre Passiflora edulis Sims (maracujá-roxo), Passiflora alata Curtis (maracujá-doce), Passiflora quadrangularis L., Passiflora caerulea L. e Passiflora laurifolia L., sendo voltados para o consumo in natura e produção de sucos (IBGE 2011).

O Brasil é um dos maiores produtores de maracujá, com uma área plantada, em 2007, em torno de 47 mil e produtividade média em torno

\footnotetext{
'Trabalho Sinfruit 118 - Simpósio Internacional de Fruticultura - Avanços na Fruticultura (17 a 21 Outubro)

${ }^{2}$ Mestrando em Produção Vegetal, UENF/CCTA/LFIT, 28013-603, Campos-RJ. E-mail: pcsantos18@hotmail.com

${ }^{3}$ Eng. Agrônomo, UENF/CCTA/ LFIT, 28013-603, Campos-RJ. E-mail: lcarniello@yahoo.com.br

${ }^{4}$ DSc em Produção Vegetal, UENF/CCTA/LFIT, 28013-603, Campos-RJ. E-mail: freitassj@yahoo.com.br

${ }^{5}$ Mestranda em Genética e Melhoramento Vegetal. UENF/CCTA/LEAG, 28013-603, Campos-RJ. E-mail: lilianeuenf@hotmail.com

${ }^{6}$ DSc em Produção Vegetal, Professor de Fruticultura, UENF/CCTA/LFIT, 28013-602, Campos-RJ. E-mail: almy@uenf.br
} 
de $14 \mathrm{t} \mathrm{ha}^{-1}$ ano $^{-1}$. O Rio de Janeiro, em 2007, tinha uma área plantada de 690 ha, com produtividade média em torno de $17 \mathrm{t} \mathrm{ha}^{-1}$ ano $^{-1}$. Apesar de todo o potencial para o cultivo desta fruteira no Estado do Rio de Janeiro, verifica-se, nas informações do IBGE (2011), redução significativa de produção e área plantada nos últimos anos. Ressalta-se, ainda, que a produtividade média brasileira é considerada baixa, visto que o potencial produtivo da cultura pode alcançar 40 a $50 \mathrm{t} \mathrm{ha}^{-1}$, com a utilização adequada de irrigação e adubação (CARVALHO et al., 1999 e 2000).

A adubação, frequentemente, aumenta as produções agrícolas, devido ao aumento do vigor vegetal (ESPINDULA et al., 2010). No entanto, a prática de adubação deve exigir conhecimentos sobre as características morfofisiológicas da planta, além daquelas relacionadas com a disponibilidade dos nutrientes no solo e com seu comportamento na planta (ALMEIDA et al., 2007), podendo os nutrientes ser fornecidos através da adubação orgânica ou pela adubação mineral.

Pires et al. (2009), empregando adubos orgânicos no cultivo do maracujazeiro-amarelo, verificaram que as plantas apresentaram produtividade, qualidade dos frutos e teores foliares de $\mathrm{P}, \mathrm{Ca}$, $\mathrm{Cu}, \mathrm{Fe}, \mathrm{Mo}$ e $\mathrm{Zn}$ semelhantes às plantas submetidas à adubação química tradicional. Além disso, a adubação orgânica tem influência positiva sobre as propriedades químicas, físicas e biológicas do solo.

O nitrogênio participa de diversos compostos considerados indispensáveis para o crescimento e desenvolvimento das plantas, destacando-se as proteínas e as clorofilas (TAIZ; ZEIGER, 2009). Segundo Bredemeier e Mundstock (2000), a quantidade absorvida varia durante o ciclo de desenvolvimento da planta em função da quantidade de raízes e da taxa de absorção por unidade de peso de raiz.

A absorção do nitrogênio, nutriente de alta mobilidade no solo, ocorre tanto na forma de cátion (amônio - $\mathrm{NH}_{4}^{+}$) como na de ânion (nitrato - $\mathrm{NO}_{3}^{-}$) (LOBO et al., 2011). A forma amoniacal possui a vantagem de se fixar às partículas coloidais do solo, principalmente às partículas de argila que são carregadas negativamente na periferia. Além disso, esta forma requer menos energia para a absorção do que o nitrato (ZHOU et al., 2011). Já o nitrogênio nítrico é totalmente solúvel em água, não se fixa nas argilas e é facilmente lixiviado no solo (MALAVOLTA, 2006).

Em relação às fontes de adubos nitrogenados utilizados para a adubação do maracujazeiro, estes diferem principalmente em razão da presença de outro nutriente ou pelo efeito que exercem sobre o $\mathrm{pH}$ do solo, devendo a escolha basear-se na disponi- bilidade do produto no mercado, preço, época, modo de aplicação e sistemas de manejo, dentre outros fatores (BORGES et al., 2006).

Entre os fertilizantes nitrogenados sólidos no mercado mundial, a ureia é a fonte mais usada, destacando-se pela facilidade de acesso, menor custo por unidade de $\mathrm{N}(45 \%$ de $\mathrm{N})$, elevada solubilidade e compatibilidade para a mistura com outros fertilizantes e defensivos, e alta taxa de absorção foliar. Porém, o N é perdido com muita facilidade por volatilização de $\mathrm{NH}_{3}$, além de acidificar o substrato (CANTARELLA, 2007).

As outras fontes mais utilizadas são sulfato de amônio $(21 \%$ de $\mathrm{N})$ e o nitrato de amônio ( $34 \%$ de N) que contém o $\mathrm{N}$ na forma amoniacal, que aplicados nos solos ácidos, tendem a manter a maior parte do $\mathrm{N}$ na forma $\mathrm{NH}_{4}^{+}$, que é estável (CANTARELLA, 2007).

A partir das informações expostas, este trabalho teve como objetivo avaliar a influência de diferentes fontes nitrogenadas sobre o crescimento inicial e teores de nutrientes foliares do maracujazeiro-amarelo.

\section{MATERIAL E MÉTODOS}

O presente experimento foi conduzido em casa de vegetação, no Câmpus da Universidade Estadual do Norte Fluminense Darcy Ribeiro. O delineamento experimental adotado foi o delineamento em blocos casualizados (DBC), com quatro repetições em fatorial $4 X 5$, sendo quatro fontes de nitrogênio (esterco bovino, esterco bovino + sulfato de amônio, esterco bovino + nitrato de amônio e esterco bovino + ureia) e cinco épocas de coleta das plantas (66; 82; 98; 111 e 127 dias após a semeadura), sendo a primeira coleta realizada 15 dias após a primeira adubação.

Vasos de $30 \mathrm{dm}^{3}$ foram preenchidos com uma mistura de solo, areia e esterco, na proporção de 1:1:1 $(\mathrm{v} / \mathrm{v})$, que apresentou as seguintes características químicas (Tabela 1).

Foram semeadas cinco sementes por vaso. A emergência das plântulas ocorreu aos 12 dias após o plantio. Quando as plantas atingiram $20 \mathrm{~cm}$ de altura, 51 dias após a semeadura, realizou-se o desbaste, deixando-se três plantas por vaso. Neste momento, foi realizada a primeira adubação com o equivalente a $5 \mathrm{~g}$ de nitrogênio por fonte utilizada, e um mês após, foi realizada segunda adubação, fornecendo o equivalente a $10 \mathrm{~g}$ de nitrogênio nas suas diferentes fontes, perfazendo um total de $15 \mathrm{~g}$ de $\mathrm{N}$, sabendo que o sulfato de amônio, o nitrato de amônio e a ureia contêm, aproximadamente, $20 \%, 34 \%$ e $45 \%$ de N, 
respectivamente.

As avaliações realizadas na planta foram: comprimento do ramo primário, diâmetro do caule, número de folhas, área foliar, índice SPAD, massa seca da parte aérea, massa seca da raiz e massa seca total. O comprimento do ramo primário foi medido a partir da superfície do solo até a gema apical por meio de trena milimetrada, e o diâmetro do caule foi determinado a $20 \mathrm{~cm}$ de altura do solo por meio de paquímetro. A massa seca das plantas, em suas diversas frações (folhas, caule e raiz), foi obtida após a secagem em estufa de circulação forçada de ar por 72 horas a $72^{\circ} \mathrm{C}$. A matéria seca da parte aérea foi obtida pelo somatório das frações do caule e folhas.

Para avaliação da área foliar, utilizou-se o medidor de área foliar de bancada modelo LI-3100 (LI-COR, Lincoln, NE, USA). Para calcular a área por folha, dividiu-se a área foliar total por planta pelo número de folhas por planta.

Para determinar o teor indireto de clorofila, foi utilizado o clorofilômetro (Índice SPAD) nas folhas do terço médio das plantas para posterior correlação com o teor de nitrogênio, já que, segundo Silva et al. (2011), a intensidade do verde (clorofila) tem relação com o teor de nitrogênio.

Para análise nutricional, todas as folhas da planta seca foram trituradas em moinho tipo Wiley com peneira de 20 mesh e armazenado em frascos hermeticamente fechados. Os nutrientes analisados foram: nitrogênio orgânico $\left(\mathrm{N}_{\mathrm{org}}\right)$, fósforo $(\mathrm{P})$, potássio $(\mathrm{K})$, cálcio $(\mathrm{Ca})$, magnésio $(\mathrm{Mg})$, de acordo com as metodologias descritas por Jackson (1965) e Malavolta et al. (1997).

Os teores dos macronutrientes das folhas do maracujazeiro-amarelo foram comparados com os teores encontrados na literatura (Tabela 2).

Os dados coletados foram submetidos à análise de variância, e as médias dos dados qualitativos, comparadas pelo teste de Tukey, a 5\% de probabilidade, e para os dados quantitativos foi utilizada a análise de regressão.

\section{RESULTADOS E DISCUSSÕES}

Observa-se, na Tabela 3, que as fontes de $\mathrm{N}$ não proporcionaram diferenças significativas para o comprimento de ramo primário e diâmetro das plantas. O nitrato de amônio, a ureia e o sulfato de amônio favoreceram o número de folhas e a área foliar total das plantas. Martins (2009), avaliando a influência de fontes nitrogenadas sobre o desenvolvimento do maracujazeiro-doce, também não encontrou diferença estatísticas para o comprimento do ramo primário e o diâmetro do caule.
De acordo com Cruz et al. (2006), a deficiência de nitrogênio pode afetar o crescimento e o desenvolvimento das plantas, principalmente por ser constituinte de proteínas e clorofilas, podendo então essas plantas não expressar todo o seu potencial, ocorrendo assim reduções significativas na taxa de formação e expansão foliar. Portanto, a menor área foliar do tratamento com esterco pode estar relacionada ao desvio na utilização de nutrientes para outros componentes, em detrimento da expansão foliar.

Observa-se que os maiores valores médios de área por folha foram obtidos no tratamento com ureia, porém não diferiram do tratamento com nitrato de amônio e sulfato de amônio. $\mathrm{O}$ tratamento contendo apenas esterco apresentou a pior média, não diferindo do tratamento contendo nitrato de amônio e sulfato de amônio (Tabela 3).

Para a medida indireta de clorofila, Índice SPAD, observou-se que plantas adubadas apenas com esterco bovino apresentaram valores inferiores àquelas que, além do esterco, receberam adubação mineral (com sulfato de amônio, nitrato de amônio ou ureia). O esterco bovino também apresentou resultado inferior em relação ao teor de nitrogênio, o que pode indicar uma relação direta entre os dois fatores (Tabelas 3 e 7). Martins (2009) também encontrou menor valor para o índice SPAD e teor de nitrogênio em folhas do maracujazeiro-amarelo submetido somente à adubação com esterco bovino. Em relação à matéria seca total da parte aérea, o tratamento contendo apenas esterco apresentou menor média.

Na Tabela 4, estão apresentadas as equações de regressão referentes ao comportamento das características biométricas avaliadas nas plantas de maracujá-amarelo no período compreendido entre 66 e 127 dias após a semeadura. Verifica-se que ocorreu redução na área por folha com o aumento da idade da planta, o que pode ter sido causado devido ao aumento do número de folhas por planta.

O tratamento contendo apenas esterco apresentou a menor média para a massa seca do caule e folha. As fontes de nitrogênio (nitrato de amônio, ureia e sulfato de amônio) influenciaram negativamente a massa seca das raízes (Tabela 5), o que pode ter ocorrido devido às mudanças que estas fontes exercem no pH do solo, e também a deficiência de nitrogênio no solo pode ter promovido o estímulo para expansão radicular. Souza et al. (2007) observaram que doses elevadas de ureia tiveram efeito depressivo no desenvolvimento radicular de mudas de maracujazeiro-doce. Martins (2009) encontrou resultado negativo da ureia quando comparado com outras fontes nitrogenadas, para o desenvolvimento 
radicular em maracujazeiro-doce.

Para os teores foliares de P e K (Tabela 5), não houve diferença entre os tratamentos nem entre as épocas de avaliação, estando os valores dentro das faixas encontradas por outros autores (Tabela 2). Os teores de $\mathrm{P}$ e $\mathrm{K}$ nas folhas do maracujazeiro-amarelo decresceram com o aumento da idade das plantas (Tabela 7), o que pode ter ocorrido devido à redistribuição destes nutrientes no decorrer do desenvolvimento da planta, já que os referidos nutrientes estavam bem supridos no substrato utilizado (Tabela 1).

Os teores de Ca obtidos não foram diferentes entre os tratamentos (Tabela 5) e foram maiores do que os encontrados por Carvalho et al. (2002) em condições de campo.

Em relação aos teores de $\mathrm{Mg}$, o tratamento contendo nitrato de amônio apresentou resultados maiores, quando comparado a plantas que receberam adubação apenas com esterco bovino (Tabela 5). Apesar de o tratamento apenas com esterco ter valores inferiores aos demais, os resultados obtidos estão superiores aos encontrados por Carvalho et al. (2002), que obtiveram teores $\mathrm{Mg}$ variando de 2,13 a $4,28 \mathrm{~g} \mathrm{~kg}^{-1}$ matéria seca e aos demais autores da tabela 2.

Martins (2009) encontrou maiores teores de enxofre $\left(5,65 \mathrm{~g} \mathrm{~kg}^{-1}\right.$ matéria seca) em plantas submetidas à adubação com esterco bovino acrescido de sulfato de amônio; no entanto, o presente experi- mento não apresentou diferença estatística entre os tratamentos para este nutriente (Tabela 5).

Para o nitrogênio (Tabela 6), houve interação entre as fontes nitrogenadas e a idade das plantas. Plantas colhidas com 66 dias após a semeadura não apresentaram diferentes teores de nitrogênio em função das adubações realizadas. Isto pode te ocorrido, provavelmente, devido ao fato de a planta estar em menor estádio de desenvolvimento e ao pouco intervalo de tempo entre a primeira adubação e a primeira coleta.

Observou-se, entretanto, que plantas com mais de 80 dias de plantio das sementes já apresentavam teores de $\mathrm{N}$ foliar diferentes, em função do tratamento utilizado (Tabela 6). Verificou-se, ainda, que os teores de $\mathrm{N}$ em plantas adubadas apenas com esterco bovino decresceram linearmente, enquanto aquelas adubadas com sulfato de amônio aumentaram os teores com o aumento da idade das plantas, indicando que o esterco apenas não foi capaz de suprir as demandas de $\mathrm{N}$ exigidas pelas plantas (Tabela 7). Verificou-se que, a partir da quarta coleta, os teores de $\mathrm{N}$ das plantas submetidas apenas ao esterco se encontraram abaixo da faixa encontrada por Carvalho et al. (2002), que é de 34,7 a $58 \mathrm{~g} \mathrm{~kg}^{-1}$ de matéria seca foliar. Os teores de $\mathrm{N}$ de todas as plantas que receberam adubação mineral estão dentro ou acima de faixas encontradas por Carvalho et al. (2002) e Fontes (2005).

TABELA 1 - Resultados da análise química do substrato.

\begin{tabular}{|c|c|c|c|c|c|c|c|c|c|c|c|c|c|c|}
\hline $\mathrm{pH}$ & K & $\mathrm{Ca}$ & $\mathrm{Mg}$ & $\mathrm{Al}$ & $\mathrm{H}+\mathrm{Al}$ & SB & V & $\mathrm{P}$ & $\mathrm{Fe}$ & $\mathrm{Cu}$ & $\mathrm{Zn}$ & $\mathrm{Mn}$ & ${\mathrm{S}-\mathrm{SO}^{4}}^{4}$ & B \\
\hline \multirow{2}{*}{6,6} & \multicolumn{6}{|c|}{$\mathrm{mmol}_{\mathrm{c}} \mathrm{dm}^{-3}$} & $(\%)$ & \multicolumn{7}{|c|}{$\mathrm{mg} \mathrm{dm}{ }^{-3}$} \\
\hline & 23,1 & 29,2 & 32,0 & 0 & 16,1 & 86,5 & 84 & 150 & 38,25 & 0,66 & 4,72 & 20,04 & 0,54 & 0,49 \\
\hline
\end{tabular}

Matéria orgânica $=34,65 \mathrm{~g} \mathrm{dm}^{-3}$

Análises realizadas pelo Laboratório de Análise de Solos da Fundenor, Campos dos Goytacazes-RJ.

TABELA 2 - Faixas de concentração de macronutrientes, em $\mathrm{g} \mathrm{kg}^{-1}$, observados em folhas de maracujazeiro, em diferentes estudos

\begin{tabular}{lcccccc}
\hline Autores & $\mathbf{N}$ & $\mathbf{P}$ & $\mathbf{K}$ & $\mathbf{C a}$ & $\mathbf{M g}$ & $\mathbf{S}$ \\
\hline Carvalho et al., 2000 & $34,7-49,8$ & $2,31-3,43$ & $23,5-35,5$ & $10,6-15,1$ & $2,13-3,62$ & $3,19-4,33$ \\
Carvalho et al., 2002 & $34,7-58,0$ & $2,31-3,85$ & $24,1-38,0$ & $6,13-14,4$ & $2,13-4,28$ & $3,11-4,64$ \\
Alves, 2003 & $44,3-53,5$ & $2,46-3,25$ & $18,4-29,3$ & $9,6-13,8$ & $2,68-3,92$ & $2,91-4,82$ \\
Fontes 2005 & $48,8-58,7$ & $2,47-2,96$ & $17,3-20,9$ & $9,91-13,1$ & $3,34-4,04$ & $3,96-5,07$ \\
Martins, 2009 & $32,7-48,9$ & $2,19-2,93$ & $29,8-33,4$ & $9,51-19,34$ & $3,65-6,46$ & $2,89-5,65$ \\
Moraes et al., 2011 & $31,3-36,5$ & $2,14-3,01$ & $26,8-44,7$ & $3,88-6,47$ & $2,55-3,55$ & - \\
\hline
\end{tabular}


TABELA 3 - Efeito das fontes de N sobre a área por folha (A/F), Índice SPAD, massa seca da parte aérea (MSPA) o comprimento do ramo primário (CRP), diâmetro do caule (D), número de folhas por planta (NF) e área foliar total (AFT) do maracujazeiro-amarelo, aos 127 após a semeadura

\begin{tabular}{|c|c|c|c|c|c|c|c|}
\hline Fontes de $\mathbf{N}$ & $\mathrm{A} / \mathrm{F}\left(\mathrm{cm}^{2}\right)$ & SPAD & MSPA (g) & CRP (cm) & $\mathbf{D}(\mathrm{mm})$ & NF & $\operatorname{AFT}\left(\mathrm{cm}^{2}\right)$ \\
\hline Esterco + Nitrato de amônio & $132,1 \mathrm{ab}$ & $56,36 \mathrm{a}$ & 29,47 a & 234,9 a & $5,59 \mathrm{a}$ & $24,70 \mathrm{a}$ & 3464 a \\
\hline Esterco + Ureia & $138,4 \mathrm{a}$ & $57,17 \mathrm{a}$ & 29,59 a & $232,5 \mathrm{a}$ & $5,68 \mathrm{a}$ & $24,50 \mathrm{a}$ & 3572 a \\
\hline Esterco + Sulfato de amônio & $134,4 \mathrm{ab}$ & $59,02 \mathrm{a}$ & 27,79 a & 225,5 a & 5,49 a & $24,70 \mathrm{a}$ & 3478 a \\
\hline Esterco bovino & $121,4 \mathrm{~b}$ & $48,04 \mathrm{~b}$ & $22,79 \mathrm{~b}$ & $220,7 \mathrm{a}$ & $5,53 \mathrm{a}$ & $21,85 \mathrm{~b}$ & $2735 \mathrm{~b}$ \\
\hline Média & 131,6 & 55,15 & 27,41 & 228,4 & 5,57 & 23,92 & 3312 \\
\hline CV $(\%)$ & 11,81 & 6,10 & 14,41 & 11,9 & 6,38 & 10,69 & 14,58 \\
\hline
\end{tabular}

Médias seguidas de mesma letra minúscula nas colunas não diferem entre si, pelo teste de Tukey $(\mathrm{P}>5 \%)$

TABELA 4 - Equações de regressão e respectivos coeficientes de determinação, mostrando o desenvolvimento do maracujazeiro-amarelo, em função da idade da planta.

\begin{tabular}{lllc}
\hline Características & Fontes & \multicolumn{1}{c}{ Equação } & $\mathbf{R}^{\mathbf{2}}$ \\
\hline $\begin{array}{l}\text { Comprimento do ramo } \\
\text { principal }(\mathrm{cm})\end{array}$ & Média & $\mathrm{Y}=0,0045 \mathrm{x}^{2,36}$ & $0,96^{* *}$ \\
\hline Diâmetro do caule $(\mathrm{mm})$ & Média & $\mathrm{Y}=0,3155 \mathrm{x}^{0,6304}$ & $0,96^{* *}$ \\
\hline Número de folhas & Média & $\mathrm{Y}=0,0595 \mathrm{x}^{1,3119}$ & $0,97^{* *}$ \\
\hline Área foliar total $\left(\mathrm{cm}^{2}\right)$ & Média & $\mathrm{Y}=0,1196 \mathrm{x}^{2,2279}$ & $0,92^{* *}$ \\
\hline Área por folha $\left(\mathrm{cm}^{2}\right)$ & Média & $\mathrm{Y}=-234+6,80 \mathrm{x}-0,029 \mathrm{x}^{2}$ & $0,98^{*}$ \\
\hline Índice SPAD & Média & $\mathrm{Y}=14,12+0,7249 \mathrm{x}-0,0029 \mathrm{x}^{2}$ & $0,84^{*}$ \\
\hline Matéria seca da parte aérea $(\mathrm{g})$ & Média & $\mathrm{Y}=1,452-0,3137 \mathrm{x}+0,0058 \mathrm{x}^{2}$ & $0,99^{* *}$ \\
\hline Matéria seca de caule $(\mathrm{g})$ & Média & $\mathrm{Y}=15,6-0,5386 \mathrm{x}+0,0051 \mathrm{x}^{2}$ & $0,99^{*}$ \\
\hline Matéria seca de folha $(\mathrm{g})$ & Média & $\mathrm{Y}=-20,2+0,3565 \mathrm{x}$ & $0,99^{*}$ \\
\hline Matéria seca de raiz $(\mathrm{g})$ & Média & $\mathrm{Y}=0,00000029 \mathrm{x}^{3,4941}$ & $0,99^{* *}$ \\
\hline
\end{tabular}

*e ** Significativo em nível de $5 \%$ e $1 \%$ de probabilidade, respectivamente, pelo teste $\mathrm{F}$.

TABELA 5 - Teores foliares de P, K, Ca, Mg e S no maracujazeiro-amarelo, em função da fonte de nitrogênio utilizada

\begin{tabular}{|c|c|c|c|c|c|c|c|c|}
\hline \multirow{2}{*}{ Fontes de N } & \multirow{2}{*}{ MSC (g) } & \multirow{2}{*}{$\operatorname{MSF}(\mathrm{g})$} & \multirow{2}{*}{$\operatorname{MSR}(\mathrm{g})$} & $\mathbf{P}$ & $\mathbf{K}$ & $\mathbf{C a}$ & Mg & $\mathbf{S}$ \\
\hline & & & & \multicolumn{5}{|c|}{$\mathrm{g} \mathrm{kg}^{-1}$} \\
\hline Esterco + Nitrato de amônio & $14,52 \mathrm{a}$ & $14,95 \mathrm{a}$ & $2,88 \mathrm{~b}$ & $4,08 \mathrm{a}$ & $36,32 \mathrm{a}$ & $18,02 \mathrm{a}$ & $6,92 \mathrm{a}$ & $3,36 \mathrm{a}$ \\
\hline Esterco + Ureia & $14,17 \mathrm{a}$ & $15,42 \mathrm{a}$ & $2,89 \mathrm{~b}$ & $3,98 \mathrm{a}$ & $37,50 \mathrm{a}$ & $16,44 \mathrm{a}$ & $6,56 \mathrm{ab}$ & $3,52 \mathrm{a}$ \\
\hline Esterco + Sulfato de amônio & $12,94 \mathrm{ab}$ & $14,84 \mathrm{a}$ & $2,46 \mathrm{~b}$ & $4,31 \mathrm{a}$ & $34,82 \mathrm{a}$ & $16,27 \mathrm{a}$ & $6,40 \mathrm{ab}$ & $3,71 \mathrm{a}$ \\
\hline Esterco bovino & $11,90 \mathrm{~b}$ & $10,89 \mathrm{~b}$ & $3,55 \mathrm{a}$ & $4,02 \mathrm{a}$ & $36,78 \mathrm{a}$ & $16,84 \mathrm{a}$ & $6,00 \mathrm{~b}$ & $3,07 \mathrm{a}$ \\
\hline Média & 13,38 & 14,02 & 2,95 & 4,10 & 36,35 & 16,89 & 6,49 & 3,41 \\
\hline $\mathrm{CV}(\%)$ & 18,31 & 13,68 & 23,41 & 11,11 & 36,36 & 12,89 & 12,84 & 22,98 \\
\hline
\end{tabular}

Médias seguidas de mesma letra minúscula nas colunas não diferem entre si, pelo teste de Tukey (P> 5\%). 
TABELA 6 - Teores foliares de N, em $\mathrm{g} \mathrm{kg}^{-1}$, no maracujazeiro-amarelo, em função da fonte de nitrogênio utilizada e da idade da planta

\begin{tabular}{lllllll}
\hline & \multicolumn{7}{c}{ Dias após a semeadura } \\
\cline { 2 - 7 } Fontes de N & $\mathbf{6 6}$ & $\mathbf{8 2}$ & $\mathbf{9 8}$ & $\mathbf{1 1 1}$ & $\mathbf{1 2 7}$ & Média \\
\hline Esterco + Nitrato de amônio & $51,08 \mathrm{a}$ & $55,15 \mathrm{a}$ & $54,32 \mathrm{a}$ & $56,19 \mathrm{a}$ & $57,29 \mathrm{ab}$ & 54,81 \\
Esterco + Ureia & $49,98 \mathrm{a}$ & $53,16 \mathrm{ab}$ & $49,84 \mathrm{a}$ & $56,86 \mathrm{a}$ & $49,97 \mathrm{~b}$ & 51,96 \\
Esterco + Sulfato de amônio & $52,08 \mathrm{a}$ & $54,65 \mathrm{ab}$ & $58,59 \mathrm{a}$ & $63,02 \mathrm{a}$ & $61,49 \mathrm{a}$ & 57,97 \\
Esterco bovino & $46,04 \mathrm{a}$ & $45,57 \mathrm{~b}$ & $36,22 \mathrm{~b}$ & $33,43 \mathrm{~b}$ & $30,41 \mathrm{c}$ & 38,33 \\
\hline Média & 49,79 & 52,13 & 49,74 & 52,37 & 49,79 & 50,77 \\
CV (\%) & & \multicolumn{7}{c}{9,77} \\
\hline
\end{tabular}

Médias seguidas de mesma letra minúscula nas colunas não diferem entre si, pelo teste de Tukey $(\mathrm{P}>5 \%)$.

TABELA 7 - Equações de regressão e respectivos coeficientes de determinação, mostrando os teores de nutrientes do maracujazeiro-amarelo, em função das fontes de $\mathrm{N}$ e da idade da planta

\begin{tabular}{lllc}
\hline Nutriente & Fontes & Equação & $\mathbf{R}^{\mathbf{2}}$ \\
& Nitrato de amônio & $\mathrm{Y}=54,8$ & - \\
& Uréia & $\mathrm{Y}=51,9$ & - \\
$\mathrm{N}\left(\mathrm{g} \mathrm{kg}^{-1}\right)$ & Sulfato de amônio & $\mathrm{Y}=40,7+0,1812 \mathrm{x}$ & $0,88^{* *}$ \\
& Esterco bovino & $\mathrm{Y}=65,8-0,2893 \mathrm{x}$ & $0,93^{* *}$ \\
\hline $\mathrm{P}\left(\mathrm{g} \mathrm{kg}^{-1}\right)$ & Média & $\mathrm{Y}=6,61-0,0265 \mathrm{x}$ & $0,95^{* *}$ \\
\hline $\mathrm{K}\left(\mathrm{g} \mathrm{kg}^{-1}\right)$ & Média & $\mathrm{Y}=56,1-0,208 \mathrm{x}$ & $0,95^{* *}$ \\
\hline $\mathrm{Ca}\left(\mathrm{g} \mathrm{kg}^{-1}\right)$ & Média & $\mathrm{Y}=-7,1154+0,4707 \mathrm{x}-0,00218 \mathrm{x}^{2}$ & $0,94^{* *}$ \\
\hline $\mathrm{Mg}\left(\mathrm{g} \mathrm{kg}^{-1}\right)$ & Média & $\mathrm{Y}=-3,6582+0,1972 \mathrm{x}-0,00091 \mathrm{x}^{2}$ & $0,90^{* *}$ \\
\hline $\mathrm{S}\left(\mathrm{g} \mathrm{kg}^{-1}\right)$ & Média & $\mathrm{Y}=3,41$ & - \\
\hline
\end{tabular}

*e ** Significativo em nível de $5 \%$ e $1 \%$ de probabilidade, respectivamente, pelo este $\mathrm{F}$.

\section{CONCLUSÕES}

O tratamento contendo apenas esterco bovino apresentou menor número de folhas por planta, menor área foliar, menor massa seca da parte aérea, menores valores de índice SPAD e os menores teores de $\mathrm{N}$ e $\mathrm{Mg}$, quando comparado com os demais tratamentos. Para massa seca de raiz, as plantas submetidas ao tratamento com apenas esterco bovino apresentaram resultados superiores.

\section{REFERÊNCIAS}

ALMEIDA, E.L.P.; DAMATTO JÚNIOR, E.R.; LEONEL, S. Nutrição mineral e adubação. In: LEONEL, S.; SAMPAIO, A.C. (Ed.). Maracujá doce: aspectos técnicos e econômicos. Jaboticabal: UNESP, 2007. p.59-71.
BORGES, A.L.,; CALDAS, R.C.; LIMA, A.A. Doses e fontes de nitrogênio em fertirrigação no cultivo do maracujá-amarelo. Revista Brasileira de Fruticultura, Jaboticabal, v.28, n.2, p.301-304, 2008.

BREDEMEIER, C.; MUNDSTOCK, C. M. Regulação da absorção e assimilação do nitrogênio nas plantas. Ciencia Rural, Santa Maria, v.30, n .2, p. 365-372, 2000 .

Cantarella, H. Uso de inibidor de urease para aumentar a eficiência da uréia. In: SIMPÓSIO SOBRE INFORMAÇÕES RECENTES PARA OTIMIZAÇÃO DA PRODUÇÃO AGRÍCOLA, 2007, Piracicaba. Anais... 
CARVALHO, A.J.C. DE, MONNERAT, P.H., MARTINS, D.P., BERNARDO, S. Teores foliares de nutrientes no maracujazeiro-amarelo em função de adubação nitrogenada, irrigação e épocas de amostragem. Scientia Agrícola, Piracicaba, v.59, n.1, p.121-127, 2002.

CARVALHO, A.J.C. de; MONNERAT, P.H.; MARTINS, D.P.; BERNARDO, S. Produtividade e qualidade do maracujazeiro- amarelo em resposta à adubação potássica sob lâminas de irrigação. Revista Brasileira de Fruticultura, Jaboticabal, v.21, n.3, p.333-337, 1999

CARVALHO, A.J.C.; MARTINS, D.P.; MONNERAT, P.H.; BERNARDO, S. Adubação nitrogenada e irrigação no maracujazeiro-amarelo. I. Produtividade e qualidade dos frutos. Pesquisa Agropecuária Brasileira, Brasília, v.35, n.6, p.1101-1108, 2000.

COSTA, A.F.S.; COSTA, A.N.; VENTURA, J.A.; FANTON, C.J.; LIMA, I. M.; CAETANO, L.C.S.; SANTANA, E.N. Recomendações técnicas para o cultivo do maracujazeiro. Vitória: Incaper, 2008. 56 p. (Documentos, 162)

CRUZ, J.L. Influência da salinidade sobre o crescimento, absorção e distribuição de sódio, cloro e macronutrientes em plântulas de maracujazeiro amarelo. Revista Bragantia, Campina, v.65, n.2, p.275-284, 2006.

ESPINDULA, M.C. et al . Doses e formas de aplicação de nitrogênio no desenvolvimento e produção da cultura do trigo. Ciência Agrotécnica, Lavras, v. 34 , n. $6,2010$.

FONTES, P.S.F. Eficiência da fertirrigação com nitrogênio e avaliação do estado nutricional do maracujazeiro-amarelo utilizando o DRIS. Campos dos Goytacazes - RJ. 2005. 100 f. Tese (Doutorado em Produção Vegetal) - Universidade Estadual do Norte Fluminense Darcy Ribeiro, Campos dos Goytacazes, 2005.

IBGE. Sistema IBGE de recuperação automática - Sidra. Produção agrícola municipal: produção de maracujá. 2011. Disponível em: <http://www.sidra. ibge.gov.br/>. Acesso em: 31 ago. 2011.
JACKSON, M.L. Soil chemical analysis. New Jersey: Prentice Hall, 1965.

LOBO, A. K. M.; MARTINS, M DE O.; LIMA NETO, M. C.; BONIFÁCIO, A.; SILVEIRA, J. A. G DA. Compostos nitrogenados e carboidratos em sorgo submetido à salinidade e combinações de nitrato e amônio. Revista Ciência Agronômica, Fortaleza, v. 42, n. 2, p. 390-397, 2011.

MALAVOLTA, E. Manual de nutrição mineral de plantas. São Paulo: Editora Agronômica Ceres, 2006. 638p.

MARTINS, C.M. Crescimento, nutrientes e teor de vitexina em Passifloraceas em função de adubação nitrogenada. 2009. 87 f. Tese (Doutorado em Produção Vegetal) - Universidade Estadual do Norte Fluminense Darcy Ribeiro, Campos dos Goytacazes, 2009.

MORAES, J. C. B.; SALCEDO, I. H.; SOUSA, V. F. Doses de potássio por gotejamento no estado nutricional do maracujazeiro. Revista Brasileira de Engenharia Agrícola e Ambiental. Campo Grande. v. 15, n.8, 763-770, 2011.

PIRES, A. A.; MONNERAT, P. H.; PINHO, L. G. DE R.; ZAMPIROLLI, P. D.; ROSA, R. C. C.; MUNIZ R.A. Efeito da adubação alternativa sobre os componentes de produção do maracujazeiro-amarelo. Acta Scientiarum. Agronomy, Maringá, v. 31, n. 4, p. 655-660, 2009.

SILVA, M. C. DE C.; COELHO, F. S.; BRAUN, H.; FONTES, P. C. R. Índice SPAD em função de diferentes horários e posições no folíolo da batata sob fertilização nitrogenada. Revista Ciência Agronômica, Fortaleza, v. 42, n. 4, p. 971-977, 2011.

TAIZ, L.; ZEIGER, E. Fisiologia vegetal. Porto Alegre: Ed Artmed, 2009. 848 p.

ZHOU, Y.; ZHANG, Y.; WANG, X.; CUI, J.; XIA, $\mathrm{X}$; SHI, K.; YU, J. Effects of nitrogen form on growth, $\mathrm{CO} 2$ assimilation, chlorophyll fluorescence, and photosynthetic electron allocation in cucumber and rice plants. Journal of Zhejiang UniversityScience B, Hangzhou. v.12, n. 2, p. 126-134, 2011. 